\title{
The Crystal Structure of AuCuSn
}

\author{
O. B. Karlsen, A. Kjekshus, ${ }^{\star}$ C. Rømming and E. Røst
}

Department of Chemistry, University of Oslo, Blindern, N-0315 Oslo 3, Norway

\begin{abstract}
Karlsen, O. B., Kjekshus, A., Rømming, C. and Røst, E., 1992. The Crystal Structure of AuCuSn. - Acta Chem. Scand. 46: 442-445.

The crystal structure of AuCuSn has been determined by direct methods. AuCuSn takes the $\mathrm{La}_{2} \mathrm{Sb}$-type structure with $a=407.8(1)$ and $c=1293.8(3) \mathrm{pm}$, space group $14 / \mathrm{mmm}$, Au in $4 e$ with $z=0.13116(6), 0.95 \mathrm{Cu}+0.05 \mathrm{Au}$ in $4 c$ and $\mathrm{Sn}$ in $4 e$ with $z=$ $0.3408(1)$, all values referring to a specimen with composition $\mathrm{Au}_{349} \mathrm{Cu}_{318} \mathrm{Sn}_{333}$. The results are discussed in relation to the $\mathrm{La}_{2} \mathrm{Sb}$ - and $\mathrm{Cu}_{2} \mathrm{Sb}$-type families.
\end{abstract}

Three genuine ternary phases, labelled $\mathrm{A}, \mathrm{B}$ and $\mathrm{C}$, have recently been discovered in the $\mathrm{Au}-\mathrm{Cu}-\mathrm{Sn}$ system. ${ }^{1-3} \mathrm{~A}$ and $B$ are found at, or around, 20 atom \% $\mathrm{Sn}$ and $\mathrm{C}$ at 33.3 atom \% Sn. Documentational data for identification of these phases are reported in Ref. 2, and their fitting into the $\mathrm{Au}-\mathrm{Cu}-\mathrm{Sn}$ phase diagram is dealt with in Ref. 3.

The present communication concerns the crystal structure of phase $\mathrm{C}$. Phase $\mathrm{C}$ is not stable above $370^{\circ} \mathrm{C}$ and has a virtually fixed content of 33.3 atom \% $\mathrm{Sn}$ and a narrow homogeneity range with respect to $\mathrm{Au}$ and $\mathrm{Cu}$ (33.0-37.0 atom $\%$ Au at $360^{\circ} \mathrm{C}$ ). Hereafter phase $\mathrm{C}$ will be referred to as AuCuSn.

\section{Sample provenance}

Samples were made by melting together appropriate amounts of the ( $>99.9 \%$ pure $)^{2,3}$ elements in sealed, evacuated silica-glass tubes. After quenching into ice water the samples were annealed for about one week at $360^{\circ} \mathrm{C}$. This treatment gave rather coarse-grained samples. Several fragments, obtained by cautious crushing of the samples, were checked by the Weissenberg technique. The single crystal fragment chosen for the structure determination was taken from a sample with composition $\mathrm{Au}_{349} \mathrm{Cu}_{318} \mathrm{Sn}_{333}$.

\section{X-Ray data and structure determination}

Crystal and experimental data are given in Table 1. Unit cell dimensions were calculated from diffractometer setting angles of 15 general reflections with $32.5<2 \theta<45.5^{\circ}$, the numerical values in Table 1 confirming that the nominal composition of the crystal is consistent with the compositional variation of the unit cell dimensions for phase $C$ in Ref. 3. Intensities were recorded for an octant of reciprocal space and corrected for Lorentz and polarization effects. The structure was determined by direct methods ${ }^{4}$ and refined by least-squares calculations ${ }^{5}$ using isotropic thermal

* To whom correspondence should be addressed. parameters. The data were then corrected for absorption through empirical methods ${ }^{6}$ (minimum and maximum absorption correction 0.688 and 1.628 , respectively) and the intensities of equivalent reflections averaged. The positional and anisotropic thermal parameters were finally refined by least-squares calculations. The occupation factor for the atoms in the mixed $\mathrm{Cu}$ and $\mathrm{Au} 4 c$ position was kept constant at the composition value for the crystal during the refinements. (According to the pycnometric density ${ }^{2}$ there are 12 atoms in the unit cell, which for the actual composition gives 4.19 $\mathrm{Au}, 3.81 \mathrm{Cu}$ and $4.00 \mathrm{Sn}$, viz. $3.81 \mathrm{Cu}$ and $0.19 \mathrm{Au}$ are accommodated in the mixed position.)

Figures of merit are listed in Table 1, and final parameters are given in Table 2. The thermal parameter for the mixed $\mathrm{Cu}$ and $\mathrm{Au}$ position is found to be somewhat larger than for the other atoms. This may be caused by a small error in the occupation factor, which is strongly correlated to the thermal parameter in the least-squares procedure.

Table 1. Crystal and experimental data for $\mathrm{Au}_{349} \mathrm{Cu}_{318} \mathrm{Sn}_{333}$.

\begin{tabular}{|c|c|}
\hline Diffractometer & SYNTEX $P \overline{1}$ \\
\hline Radiation & MoK $\alpha(\lambda=71.069 \mathrm{pm})$ \\
\hline Crystal system & Tetragonal \\
\hline a/pm & $407.8(1)$ \\
\hline c/pm & $1293.8(3)$ \\
\hline$V / p^{3}$ & $2.1517(9) \times 10^{8}$ \\
\hline Space group & $14 / \mathrm{mmm}$ (No. 139) \\
\hline Crystal size/mm & $0.04 \times 0.085 \times 0.235$ \\
\hline$\mu($ MoK $\alpha) / \mathrm{cm}^{-1}$ & 944 \\
\hline Scan mode & $\theta / 2 \theta$ \\
\hline Scan speed $(2 \theta) /{ }^{\circ} \min ^{-1}$ & 2.0 \\
\hline Scan range $(2 \theta) /{ }^{\circ}$ & 2.3 \\
\hline Maximum $(\sin \theta / \lambda) / \mathrm{pm}^{-1}$ & $9.0 \times 10^{-3}$ \\
\hline Stability monitoring & 3 test reflections/100 observations \\
\hline $\begin{array}{l}\text { Observed reflections } \\
\quad[/>2.5 \sigma(I)]\end{array}$ & 240 \\
\hline Weighting scheme & $w=\left[\sigma^{2}(F)\right]^{-1}$ \\
\hline No. of parameters refined & 9 \\
\hline$R=\Sigma|| F_{\mathrm{o}}|-| F_{\mathrm{c}} \| / \Sigma\left|F_{\mathrm{o}}\right|$ & 0.034 \\
\hline$R_{w}=\left[\Sigma w\left(F_{0}-F_{c}\right)^{2} / \Sigma w F_{0}^{2}\right]^{1 / 2}$ & 0.043 \\
\hline$S=\left[\Sigma w\left(F_{\mathrm{o}}-F_{\mathrm{c}}\right)^{2} /(n-m)\right]^{1 / 2}$ & 2.71 \\
\hline
\end{tabular}


Table 2. Fractional coordinates for $\mathrm{Au}_{349} \mathrm{Cu}_{318} \mathrm{Sn}_{333}$, with e.s.d.s in parentheses.

\begin{tabular}{llllll}
\hline Atom & Position & $x$ & $y$ & $z$ & $U_{\theta q}{ }^{a} / 10^{6} \mathrm{pm}^{2}$ \\
\hline $\mathrm{Au}$ & $4 e$ & 0 & 0 & $0.13116(6)$ & 1.19 \\
$\mathrm{Cu}^{b}$ & $4 c$ & 0 & $\frac{1}{2}$ & 0 & 1.72 \\
$\mathrm{Sn}$ & $4 e$ & 0 & 0 & $0.3408(1)$ & 1.10
\end{tabular}

${ }^{a} U_{\mathrm{eq}}=1 / 3 \Sigma U_{i i} .{ }^{b} 0.95 \mathrm{Cu}+0.05 \mathrm{Au}$, statistically according to the actual composition of the crystal.

They could thus not both be varied during the refinements. Observed and calculated structure factors may be obtained from the authors upon request.

\section{Discussion}

An illustration of the AuCuSn crystal structure is shown in Fig. 1, and interatomic distances are listed in Table 3. The shortest $(<300 \mathrm{pm})$ interatomic distances are also marked in Fig. 1. In order to assess the coordination number (CN) of the three kinds of atoms, the radii ${ }^{7}$ of $\mathrm{Au}, \mathrm{Cu}$ and $\mathrm{Sn}$ for $\mathrm{CN}=12$ were used as a starting point (using valences of $\mathrm{I}$ for $\mathrm{Au}$ and $\mathrm{Cu}$ and $\mathrm{IV}$ for $\mathrm{Sn}$ ). The comparison of observed and estimated interatomic distances on this basis suggests that the $\mathrm{Au}-\mathrm{Au}, \mathrm{Cu}-\mathrm{Cu}$ and $\mathrm{Sn}-\mathrm{Sn}$ distances of 339.4(1), 288.4(1) and 372.0(2) pm, respectively, in Table 3 fall outside the effective coordination sphere of the atom concerned. This leads to effective coordination numbers of 9,8 and 9 for $\mathrm{Au}, \mathrm{Cu}$ and $\mathrm{Sn}$, respectively, and gives (Fig. 1) Au a mono-capped antiprismatic (4 $\mathrm{Cu}$ and $1+4 \mathrm{Sn}$ ), $\mathrm{Cu}$ a cubic (4 $\mathrm{Au}$ an $4 \mathrm{Sn}$ ) and $\mathrm{Sn}$ a tetracapped square pyramidal $(1+4 \mathrm{Au}$ and $4 \mathrm{Cu})$ coordination. (Note that the above effective coordination numbers for $\mathrm{Cu}$ and $\mathrm{Sn}$, introduced to assess their atomic sizes, differ from those derived from the unique definition of $\mathrm{CN}$ by Frank and Kasper, ${ }^{8}$ see also Ref. 9.)

Adjustments $^{7}$ to the effective coordination numbers gives radii of $140.5,122.5$ and $150.8 \mathrm{pm}$ for $\mathrm{Au}, \mathrm{Cu}$ and $\mathrm{Sn}$, respectively. Neglecting the (in any case minor) electronegativity corrections, these radii in turn lead to calculated interatomic distances of 263.0, 291.3 and $273.3 \mathrm{pm}$ for $\mathrm{Au}-\mathrm{Cu}, \mathrm{Au}-\mathrm{Sn}$ and $\mathrm{Cu}-\mathrm{Sn}$, respectively. These predictions match the observed values in Table 3 reasonably well, particularly in view of the crude model applied to a rela-

Table 3. Interatomic distances (in pm; $<400 \mathrm{pm}$ ) in $\mathrm{Au}_{349} \mathrm{Cu}_{318} \mathrm{Sn}_{333}$, numbers in parentheses corresponding to e.s.d.s in axes and positional parameters (Tables 1 and 2$)^{a}$.

$\mathrm{Au}-1 \mathrm{Au} 339.4(1) \quad \mathrm{Cu}-4 \mathrm{Au}$ 265.3(1) $\mathrm{Sn}-1 \mathrm{Au} 271.3(2)$ $\mathrm{Au}-4 \mathrm{Cu}$ 265.3(1) $\mathrm{Cu}-4 \mathrm{Cu} 288.4(1)^{b} \quad \mathrm{Sn}-4 \mathrm{Au} 290.6(2)$ $\mathrm{Au}-1 \mathrm{Sn} 271.3(2) \quad \mathrm{Cu}-4 \mathrm{Sn} 289.8(1) \quad \mathrm{Sn}-4 \mathrm{Cu} 289.8(1)$ $\mathrm{Au}-4 \mathrm{Sn} 290.6(2) \quad \mathrm{Sn}-4 \mathrm{Sn} 372.0(2)$

${ }^{a} \mathrm{Cu}$ refers to a statistical distribution of $0.95 \mathrm{Cu}+0.05 \mathrm{Au}$. ${ }^{b}$ E.s.d. depends only on e.s.d. in a axis.

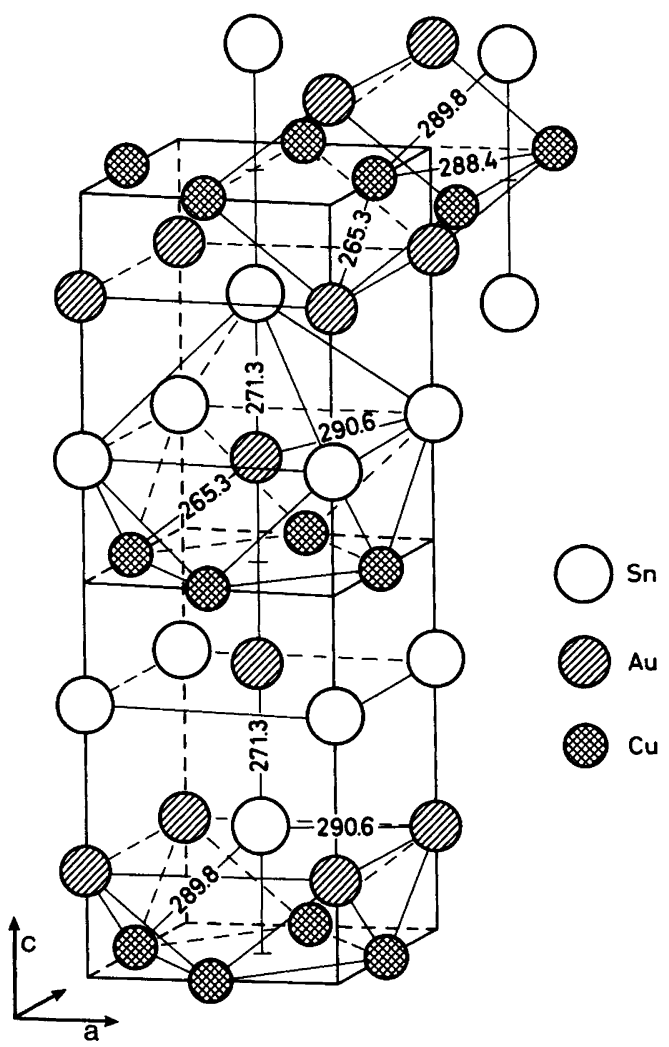

Fig. 1. The (La $\mathrm{La}_{2} \mathrm{Sb}$-type) crystal structure of AuCuSn [where $\mathrm{Au}$ corresponds to $\mathrm{Sb}, \mathrm{Cu}$ to $\mathrm{La}(1)$ and $\mathrm{Sn}$ to $\mathrm{La}(2)]$. The legend to the symbols for the atoms is given in the illustration, which also shows interatomic distances (in pm; $<300$ pm) and indicates coordination around the different kinds of atoms.

tively complex structure. The most striking manifestation of the shortcoming of the hard-sphere model in relation to AuCuSn is the marked difference $(19.3 \mathrm{pm})$ between the two sets of Au-Sn distances (which is easily accounted for if a slightly ellipsoidal shape of $\mathrm{Au}$ and/or $\mathrm{Sn}$ is introduced).

AuCuSn belongs to the $\mathrm{La}_{2} \mathrm{Sb}$-type crystal structure, ${ }^{9} \mathrm{a}$ structure family which comprises at least 38 binary members. ${ }^{10}$ The $\mathrm{La}_{2} \mathrm{Sb}$ type is in turn related to a number of other structure types (cf. Ref. 7), but here it will only be considered briefly in relation to the $\mathrm{Cu}_{2} \mathrm{Sb}$ type. The $\mathrm{La}_{2} \mathrm{Sb}$ type structure comprises two $\mathrm{Cu}_{2} \mathrm{Sb}$-type unit cells related by a mirror plane perpendicular to $c$. Fig. 2 (based on data from Ref. 10) shows the number of binary and ternary phases of the two classes of structure types distributed according to $c / a$. (To facilitate direct comparison $2 c / a$ has also been marked for the $\mathrm{Cu}_{2} \mathrm{Sb}$-type family.)

Already a first glance at Fig. 2 shows that the $\mathrm{Cu}_{2} \mathrm{Sb}$-type family is appreciably larger than the $\mathrm{La}_{2} \mathrm{Sb}$ type (ca. 5 times larger when all representatives in Ref. 10 are included). This imbalance may partly be attributed to the rather unsystematic search for members of the two families. There appears to be no simple compositional pattern in the distribution of the individual members among the two structure types (cf. Ref. 10). In the particular case of AuCuSn the 


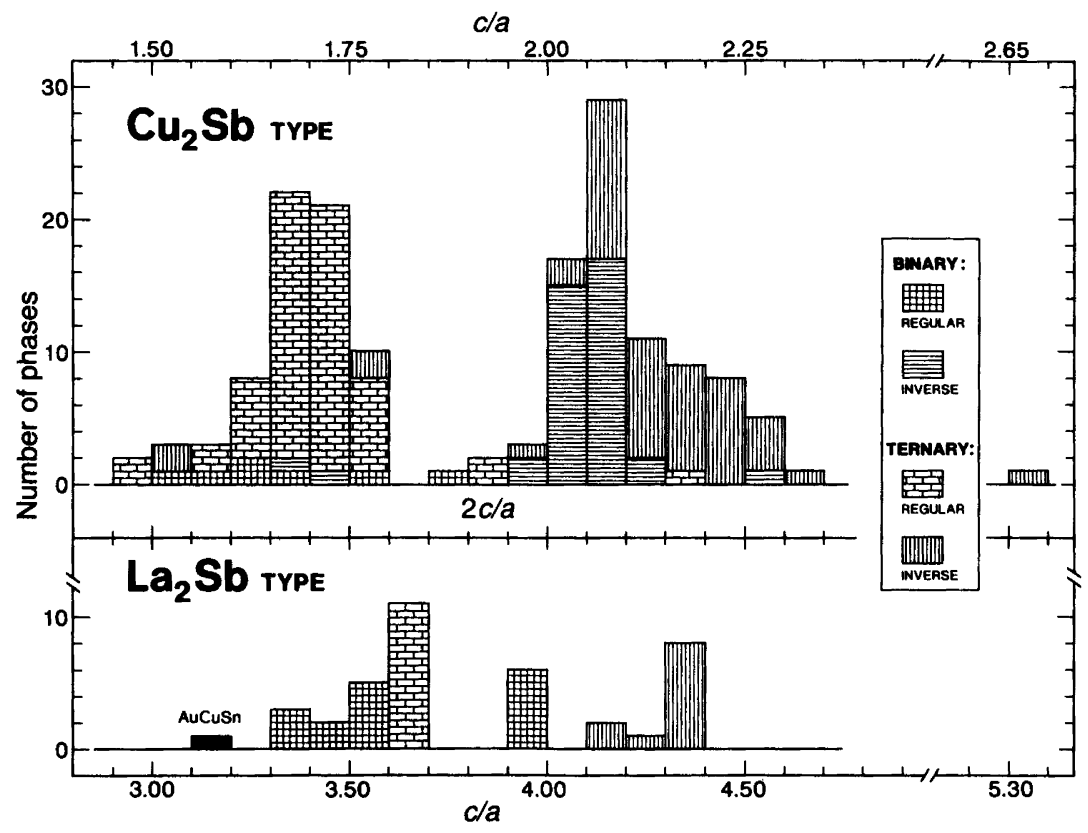

Fig. 2. Histograms showing the number of phases versus $\mathrm{c} / \mathrm{a}$ for the $\mathrm{La}_{2} \mathrm{Sb}$ - and $\mathrm{Cu}_{2} \mathrm{Sb}$-type (with $2 \mathrm{c} / \mathrm{a}$ also marked) families. A selection of 158 of the 193 representatives with the $\mathrm{Cu}_{2} \mathrm{Sb}$-type structure listed in Ref. 10 has been made in order to ensure comparable compositions. (Note that $\mathrm{Ti}_{2} \mathrm{Bi}^{9}$ is erroneously listed among the $\mathrm{Cu}_{2} \mathrm{Sb}$ class in Ref. 10.) The legend to the hatching symbols is given in the illustration.

mirror plane in question gives rise to the virtually squareplanar coordinations of $4 \mathrm{Au}$ as well as $4 \mathrm{Sn}$ around $\mathrm{Cu}$ (Fig. 1), as opposed to the corresponding tetrahedral coordinations which would have resulted if the mirror plane had been lacking. Although the preference for square-planar coordination for $\mathrm{Cu}$ could provide an attractive source for the occurrence of the mirror plane in the AuCuSn structure, this is certainly not suitable as a general explanation for the entire $\mathrm{La}_{2} \mathrm{Sb}$-type family. The origin of the mirror plane is in fact probably the key to a deeper understanding of both the $\mathrm{La}_{2} \mathrm{Sb}$ - and the $\mathrm{Cu}_{2} \mathrm{Sb}$-type families.

Fig. 2 divides the $\mathrm{La}_{2} \mathrm{Sb}$ - and $\mathrm{Cu}_{2} \mathrm{Sb}$-type families first into binary and ternary representatives, and then each of these subclasses in turn into regular and inverse variants. The Periodic System and the electronegativity scale were used as criteria for the identification of regular $\left(\mathrm{A}_{2} \mathrm{~B} ; \mathrm{AA}^{\prime} \mathrm{B}\right)$ and inverse $\left(\mathrm{AB}_{2} ; \mathrm{ABB}^{\prime}\right)$ family members. These more detailed classifications do not give rise to unambiguous distribution patterns either. True enough, the binary and ternary phases are largely smeared out over the histograms, but this is not surprising in view of the ternary crystallographic formula ( $\mathrm{AA}^{\prime} \mathrm{B}$ or $\mathrm{ABB}^{\prime}$; binary chemical compositions representing specialities thereof) which apply to these structure families. There is a relatively clear tendency for the inverse members to occur at the highest $c / a$ values in both families. Beyond the level of detail of Fig. 2, there are also tendencies which may be mentioned. First, the number of electrons per formula unit (counted according to the group number of the Periodic System) increases roughly with $c / a$. The challenge in this connection is to arrive at more reliable valence numbers for the counting of the electrons. Second, there are certain indications of rough correlations between the unconstrained positional parameters and $c / a$. The problem is here that most of the atomic coordinates for the $\mathrm{La}_{2} \mathrm{Sb}$ - and $\mathrm{Cu}_{2} \mathrm{Sb}$-type structures refer to poorly refined or even unrefined data. Third, there are also vague hints of a possible simple correlation between the atomic sizes and the unit cell dimensions. The problems here are not only the inaccurate basis of the structural data, but also the uncertainties attached to the atomic sizes.

$\mathrm{AuCuSn}$ has the lowest c/a ratio among the currently considered $\mathrm{La}_{2} \mathrm{Sb}$-type phases (Fig. 2). This may trivially be accounted for as being due to our incomplete knowledge about the $\mathrm{La}_{2} \mathrm{Sb}$-type family, but may alternatively reflect significant atomic packing details for the metallic phase AuCuSn. The smaller $\mathrm{Cu}$ atoms in the $4 c$ position join together buckled blocks of the larger $\mathrm{Au}$ and $\mathrm{Sn}$ atoms (Fig. 1). According to the interatomic distances (Table 3 and vide supra) it may be suggested that the $a$-axis is largely determined by the sizes of $\mathrm{Au}$ and $\mathrm{Sn}$ [reflected in the 'diagonal' 290.6(2) pm distance], whereas the size of $\mathrm{Cu}$ is also involved for the $c$-axis. The fact that $c$ increases relatively more than $a$ when $\mathrm{Au}$ is substituted for $\mathrm{Cu}$ in $\mathrm{Au}-$ $\mathrm{CuSn}$ lends support to this suggestion. ${ }^{3} \mathrm{~A}$ somewhat analogous case in which the atomic size difference significantly influences $c / a$ is provided by the AuCu I phase. ${ }^{11}$

An intricate question concerning the AuCuSn phase is why its homogeneity range is so limited compared with other phases in the $\mathrm{Au}-\mathrm{Cu}-\mathrm{Sn}$ system. Since Ref. 3 was completed the authors have carried out additional phase 
analytical work to ensure that a fixed $\mathrm{Sn}$ content and a maximum of ca. 12 atom \% $\mathrm{Au}$ for $\mathrm{Cu}$ substitution are also representative for the AuCuSn phase when temperature variation is taken into account. This is indeed the case, and the puzzling problem is then to explain why the rather favourable valence, size and electronegativity differences do not give rise to extensive mutual exchange between $\mathrm{Au}$ and $\mathrm{Cu}$. The fact that the exchange is one-sided (vide supra) makes this feature even more remarkable.

In conclusion it seems legitimate to insist that much more work is required before even a superficial understanding of the $\mathrm{La}_{2} \mathrm{Sb}$ - and $\mathrm{Cu}_{2}$ Sb-type families is attained.

\section{References}

1. Roeder, J. F., Notis, M. R. and Goldstein, J. I. Diffus. Defect Data, Part A 59 (1988) 271.
2. Karlsen, O. B., Kjekshus, A. and Røst, E. Acta Chem. Scand. 44 (1990) 197.

3. Karlsen, O. B., Kjekshus, A. and Røst, E. Acta Chem. Scand. 46 (1992) 147.

4. Gilmore, C. J. J. Appl. Crystallogr. 17 (1984) 42.

5. Mallinson, P. R. and Muir, K. W. J. Appl. Crystallogr. 18 (1985) 51.

6. Walker, N. and Stuart, D. Acta Crystallogr., Sect. A 39 (1983) 158.

7. Pearson, W. B. The Crystal Chemistry and Physics of Metals and Alloys, Wiley-Interscience, New York 1972.

8. Frank, F. C. and Kasper, J. S. Acta Crystallogr. 11 (1958) 184.

9. Stassen, W. N., Sato, M. and Calvert, L. D. Acta Crystallogr., Sect. B 26 (1970) 1534.

10. Villars, P. and Calvert, L. D. Pearson's Handbook of Crystallographic Data for Intermetallic Phases, American Society for Metals, Metals Park, OH 1985, Vols. 1-3.

11. Bjerkelund, E., Pearson, W. B., Selte, K. and Kjekshus, A. Acta Chem. Scand. 21 (1967) 2900.

Received October 10, 1991. 